\title{
Quantifying Effects of Spatial Heterogeneity of Farmlands on Bird Species Richness by Means of Similarity Index Pairwise
}

\author{
Federico Morelli \\ DiSTeVA, University of Urbino, Scientific Campus, 61029 Urbino, Italy \\ Correspondence should be addressed to Federico Morelli; morellius@libero.it
}

Received 6 March 2013; Revised 30 April 2013; Accepted 10 May 2013

Academic Editor: Antonio Terlizzi

Copyright (C) 2013 Federico Morelli. This is an open access article distributed under the Creative Commons Attribution License, which permits unrestricted use, distribution, and reproduction in any medium, provided the original work is properly cited.

\begin{abstract}
Many studies have shown how intensification of farming is the main cause of loss biodiversity in these environments. During the last decades, agroecosystems in Europe have changed drastically, mainly due to mechanization of agriculture. In this work, species richness in bird communities was examined on a gradient of spatial heterogeneity of farmlands, in order to quantify its effects. Four categories of farmland spatial heterogeneity were defined, based on landscape and landuse parameters. The impact of features increasing the spatial heterogeneity was quantified comparing the similarity indexes between bird communities in several farmlands of Central Italy. The effects of environmental variables on bird richness were analyzed using GLM. The results highlighted that landscape features surrogates of high nature values (HNVs) of farmlands can increase more than $50 \%$ the bird species richness. The features more related to bird richness were hedgerows, scattered shrubs, uncultivated patches, and powerlines. The results confirm that the approach based on HNV for evaluating the farmlands is also suitable in order to study birds' diversity. However, some species are more sensitive to heterogeneity, while other species occupy mainly homogeneous farmlands. As a consequence, different conservation methods must be considered for each farmland bird species.
\end{abstract}

\section{Introduction}

Agricultural intensification is one of the main drivers of biodiversity decline. During the last twenty-five years a rapid and large scale change of the agricultural landscape occurred in Europe, caused by the intensification and mechanization of agricultural activities $[1,2]$, and for this reason understanding the relations between biodiversity and land-use intensity is quite important to developed effective plans for habitat conservation [3]. Many studies about biodiversity in agroecosystems usually faced the problem that both management type and landscapes features can affect it [4-6], but a quantification of the real impact of each of these factors on the composition of animal communities is complicated. Biodiversity in farmlands is affected by land-use management at a small spatial scale (grazing intensity or crop rotation) and also at a large spatial scale [3]. All of this is related to the presence and/or distribution of landscape features that may reflect a low fragmentation of the habitat, which is often called "functional heterogeneity," and is very important in supporting biodiversity [7-11].
Many studies have shown that organic systems may enhance bird species diversity over nonorganic counterparts as a result of increased complexity in landscape features [12, 13], because in ecology the habitat diversity is associated with an increase of niche availability for the species [14]. Mainly for this reason farmers are increasingly being encouraged to conserve biodiversity through the maintenance of extensive farming systems, the preservation of seminatural landscape features, or the extension of intensive farming systems [15, 16]. However, at the moment, most of our knowledge of agricultural practices and farmland bird ecology comes from a few countries only, with $76 \%$ of papers in the Web of Science outsourcing from the UK, France, the Netherlands, Spain, Germany, and Sweden, and less than 10\% from Central and Eastern European countries [17]. The results of many of these works show that the correlation between biodiversity and agricultural heterogeneity varies from positive to negative in different systems in Europe [9, 18, 19].

The spatial heterogeneity in an agroecosystems is measurable through landscape features that can be used also to assess bird species richness, as a surrogate of biodiversity. [20]. 
The first aim of the present study is examining the relationships between bird species richness and spatial heterogeneity of farmlands in Central Italy and quantifying the impact of spatial heterogeneity on biodiversity, through the use of an index easy to apply and useful for conservation strategies.

The second aim is identifying the main environmental characteristics associated with the heterogeneity of farmlands and investigating whether the species living in heterogeneous agricultural areas are also present also in more homogeneous farmlands, to help in this way to identify the bird species most related to landscape heterogeneity as possible indicators of HNV farmlands.

\section{Material and Methods}

2.1. Study Area. The study area was an agricultural area of the North Eastern Marches region (Central Italy, $43^{\circ} 45^{\prime} 47.30^{\prime \prime} \mathrm{N}$; $12^{\circ} 45^{\prime} 5.20^{\prime \prime} \mathrm{E}$ ) that was 2,500 ha wide, ranged from 0 to $800 \mathrm{~m} / \mathrm{a} . \mathrm{s} .1$. This area was selected because it includes farmlands representative of the different farming practices in the region. Within the area 80 sites were selected randomly and surveyed. There sites were located uniformly and each far at least $500 \mathrm{~m}$ from one other.

2.2. Species and Environmental Data. To survey the bird community composition during the breeding period of the year 2010, the sites were visited in the morning within 06:00 AM and 10:00 AM, with sunny weather conditions, between mid-April and the end of July. Each visit lasted $10 \mathrm{~min}$, and all birds detected visually and acoustically within a radius of $100 \mathrm{~m}$ from the observer were recorded [21] using single point counts. Species not breeding and diurnal or nocturnal raptors were excluded from subsequent analyses, because sometimes they require different survey methods. Also occasional or not breeding species were excluded from the statistical analysis, because their presence was very rare and therefore did not affect the total richness. The only exception was Circus pygargus that was considered strongly related to the studied habitats [22, 23] and then counted into bird richness but excluded from the further environmental analysis because, if compared with passeriform birds, the species could be considered a wide-ranged species.

Description in situ of the 3 ha (100 m radius area) around the point-count was made in order to quantify the land-use composition and the structural characteristics in the sampling sites and to obtain an updated information concerning crop types. The percentages of land-use composition estimated in situ were adjusted by checking aerial photographs and using a $100 \mathrm{~m}$ radius buffer overlapped with ArcGIS 10, in order to avoid the difficulties determinated by the exclusive use of digital maps to study limited environments [24]. Also altitude of the point count was recorded, using a GPS.

2.3. Spatial Heterogeneity of Farmlands. In order to classify the farmland heterogeneity, an approach in line with that recently used for evaluating high nature value (HNV) farmland in Europe [25-28] was used. The presence and size
TABLE 1: Environmental parameters used to describe the farmlands in Central Italy. The spatial scale of measurement was $100 \mathrm{~m}$ radius around a single point count.

\begin{tabular}{|c|c|c|c|}
\hline Parameters & Abbreviation & Level & Details \\
\hline Altitude & alt & Landscape & $\begin{array}{l}\text { Altitude of the point } \\
\text { count (m/a.s.l.) }\end{array}$ \\
\hline Terrain slope & slo & Landscape & $\begin{array}{c}\text { No slope (less than } 3 \\
\text { degrees): } 0 \text {, slight slope } \\
\text { (between } 3 \text { and } 8 \\
\text { degrees): } 1 \text {, mean slope } \\
\text { (greater than } 8 \text { degrees): } \\
2\end{array}$ \\
\hline Roads & roa & Landscape & $\begin{array}{l}\text { Presence and type of } \\
\text { roads (paved and } \\
\text { unpaved) }\end{array}$ \\
\hline Power lines & pow & Landscape & $\begin{array}{c}\text { Number of electricity } \\
\text { wires }\end{array}$ \\
\hline Urban & urb & Land-use & $\%$ \\
\hline Forest & for & Land-use & $\%$ \\
\hline Shrubs & $\operatorname{shr}$ & Land-use & $\%$ \\
\hline Uncultivated & unc & Land-use & $\%$ \\
\hline Badland & bad & Land-use & $\%$ \\
\hline Grassland & gra & Land-use & $\%$ \\
\hline Hedgerows & hed & Land-use & $\%$ \\
\hline Isolated trees & tre & Land-use & $\%$ \\
\hline Vineyards & vin & Land-use & $\%$ \\
\hline Olive & oli & Land-use & $\%$ \\
\hline Cultivated total & cul & Land-use & Sum of all crop types, $\%$ \\
\hline Forage & ofo & Crop type & $\%$ \\
\hline Wheat & whe & Crop type & $\%$ \\
\hline Alfalfa & alf & Crop type & $\%$ \\
\hline Hay & hay & Crop type & $\%$ \\
\hline Sunflower & sun & Crop type & $\%$ \\
\hline Coriander & cri & Crop type & $\%$ \\
\hline Sugarbeet & sug & Crop type & $\%$ \\
\hline Corn & cor & Crop type & $\%$ \\
\hline Garlic & gar & Crop type & $\%$ \\
\hline Oats & oat & Crop type & $\%$ \\
\hline Brassica sp & bra & Crop type & $\%$ \\
\hline Lettuce & let & Crop type & $\%$ \\
\hline
\end{tabular}

of natural and seminatural farmland features (i.e., shrubs, uncultivated patches) or linear features (i.e., field margins, hedgerows) were analyzed, since they could increase the number of ecological niches in which wildlife can coexist with farming activities and create a heterogeneity gradient. The spatial features were analyzed at three different scale level: landscape diversity, land-use diversity, and crop type (Table 1).

2.3.1. Landscape Diversity. To define the landscape diversity the following parameters were used:

(1) road presence and type: paved, unpaved, or mixed;

(2) power lines: presence and number; 
TABLE 2: Ranking of farmland spatial heterogeneity according to landscape and land-uses characteristics, where FSH is farmland spatial heterogeneity.

\begin{tabular}{lcccc}
\hline FSH description & FSH rank & Terrain slope & Marginal vegetation & Land-use diversity \\
\hline Very heterogeneous & $\mathbf{4}$ & None, slight, mean & Linear + point & $>1.0$ \\
Heterogeneous & $\mathbf{3}$ & None, slight, mean & Linear & $0.8<1.0$ \\
Homogeneous & $\mathbf{2}$ & None, slight, mean & Point & $0.6<0.8$ \\
Very homogeneous & $\mathbf{1}$ & None, slight & None & $<0.6$ \\
\hline
\end{tabular}

(3) terrain slope, classified as no slope (less than 3 degrees): 0 , slight slope (between 3 and 8 degrees): 1 , and mean slope (greater than 8 degrees): 2 ;

(4) marginal vegetation level on cultivated, taking into account the presence (isolated or simultaneous) of natural and semi-natural features: max level (linear features (hedgerows) + point features (scattered shrubs)), mid-level (linear features (hedgerows)), low level (point features (scattered shrubs)), and min level (without hedgerows and scattered shrubs) (see Figure 1). The hedgerows were considered as a factor of greater level than scattered shrubs because in the study area they always resulted as larger features in relative terms, thus offering a greater edge effects on habitat fragmentation. The minimum radius size of the scattered shrubs considered in this study was 0.5 meter. The marginal vegetation is also used to define the HNV of farmlands [27, 28].

2.3.2. Land-Use Diversity. The land-use diversity in each site was calculated using Shannon diversity index on land-uses, $H^{\prime}=-\sum p_{i} \times \log p_{i}$, where $p_{i}$ is the relative proportion of each land-use type $i$ [30]. This index can express the fragmentation of land-uses as more fragmented land-use types have larger number of patches, each of a smaller average size within the sampled area.

2.3.3. Crop Type. Crop diversity was estimated for each site, applying the Shannon diversity index on crop types into the cultivated category (Table 1). However, this feature was also analyzed as another level of farmland heterogeneity, because it appears in contrast compared to the land-use (the crop diversity was greater when the land-use diversity was lower, because of being dominated by cultivated typology).

Four categories of spatial heterogeneity of farmland were defined considering both landscape and land-use data collected in situ. The sampled sites were ranked in relation to a decreasing spatial heterogeneity value as follows: very heterogeneous mosaic: 4 , heterogeneous mosaic: 3 , homogeneous mosaic: 2 , and very homogeneous mosaic: 1 (see details in Table 2). When a site could not be clearly categorized (considering all parameters in Table 2), it was classified in the closest category.

2.4. Data Analysis. Biodiversity was estimated as bird species richness at each sampled site and was estimated for each farmland heterogeneity level too. Total biodiversity was the sum of all bird species recorded in the entire study area. To

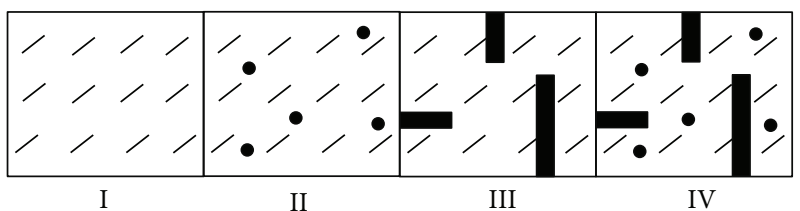

FIGURE 1: Scheme of the criteria used to classify the level of marginal vegetation of farmlands in Central Italy. The point features represent scattered shrubs while linear features represent hedgerows.

test the effects of environmental parameters (associated with farmland spatial heterogeneity) on biodiversity, bird richness in different spatial heterogeneity categories was compared using ANOVA (after doing the normality and homoscedasticity tests). Similarity between bird communities in different heterogeneity categories was explored using the Sorensen Similarity Index. The Sorensen similarity index (SI) [31] is a $\beta$ diversity index that vary from 0 where the assemblages differ totally to 1 where they are identical (SI $=2 c /(a+b)$, where $c$ is the number of species shared by the two sites, and $a$ and $b$ are the total number of species at each site). The Sorensen similarity index was calculated for pairwise comparisons between different heterogeneity categories and also between each of them and the total biodiversity. This method was used to quantify the differences on bird communities between spatial heterogeneity gradient.

The nature and strength of the relationship between bird richness and environmental parameters on farmlands were examined using GLM [32], with the dependent variable (bird richness) modeled specifying Poisson errors. Independent predictive variables were expressed as arcsin square root in the case of proportions. In order to avoid multicolinearity of land-use and crop types, the parameters (regressors) showing the strongest correlation $(>0.8)$ were manually eliminated. A stepwise backward procedure was carried out using all data pooled in order to select the best predictors using AIC criterion to select the lowest AIC values [33, 34]. In models, sites were treated as independent units, because the values of spatial autocorrelation between geographic distance and dissimilarity matrix of sites (obtained from landscapes variables) were low (Mantel test $r=0.13$, $n=80$ sites, not significant) [35]. Dissimilarity indices among sites were calculated by means of "vegdist" function of the vegan package [36], using five different landscape variables (altitude, urban, roads, hedgerows, and cultivated total). Internal validation of models was performed using a bootstrap resampling procedure $(n$ bootstrap $=999)$. All tests were performed with R program (R Development Core Team 2011). 


\section{Results}

Sixty-six bird species were recorded during the breeding period. For the analysis, a total of 1133 records were collected. The maximum potential bird richness for the studied farmland was fifty-five species (Tables 3 and 5) considering that were excluded not-breeding species, diurnal and nocturnal raptors.

The most common farmland types had high or medium spatial heterogeneity (over 73\%), whereas farmlands with lower heterogeneity were only $27 \%$ (Table 3 ), mainly distributed near the coast, in lowland zones. Roads were present in all farmlands. The most common road type was paved (64\%), while unpaved roads were $20 \%$, and mixed (paved and unpaved) roads represented $16 \%$ of cases. Power lines were widespread in farmlands (90\%), and no differences in this element were found between different farmland heterogeneity levels. The differences in crop diversity across the gradient of spatial heterogeneity were not significant (Table 4).

3.1. Effects of Spatial Heterogeneity on Bird Richness. The bird species richness on different farmland spatial heterogeneity categories was different, being higher in farmlands with greater heterogeneity ( $F: 37.8$, df: $3, P$ value: 0.000 , Figure 2 ). The most heterogeneous farmlands had a maximum richness value of fifty-one species, whereas in the most homogeneous farmlands the maximum richness value was twenty-five species.

The impact of FSH on biodiversity was quantified by means of similarity index pairwise between the FSH categories. The homogenization of farmlands was able to reduce the similarity index on bird richness up to a half compared to very heterogeneous farmlands. The total effect was quantified as a fall of circa $53 \%$ of diversity in comparison with the total amount of species and $40 \%$ between very heterogeneous and very homogeneous farmlands (Table 5). On the other hand, the difference between bird species in very heterogeneous areas and potential bird richness of farmlands was small, only $4 \%$.

\subsection{Parameters of Farmlands Useful to Explain Bird Distribu-} tion. Following the results of this work, the linear features as hedgerows were more important than point features as shrubs for the total bird richness (more dissimilarities from index were found between 1 and 3 than between 1 and 2 FSH categories) (Table 5).

The model that best described the relationships between bird species richness and environmental parameters in farmlands included three land-use variables (shrubs, uncultivated, and hedges) and one landscape variable (presence of powerlines). The ratio between explained and total deviance for the best model was 0.83 . These four parameters were statistically significant for all the farmland typologies, and if compared to the initial model including all the variables, the model with only these four variables appeared to be the most suitable. Altitude had not effect on bird diversity in the study area. The results of backwise procedure have not selected altitude as variable related to the bird species richness (Tables 6 and 7).

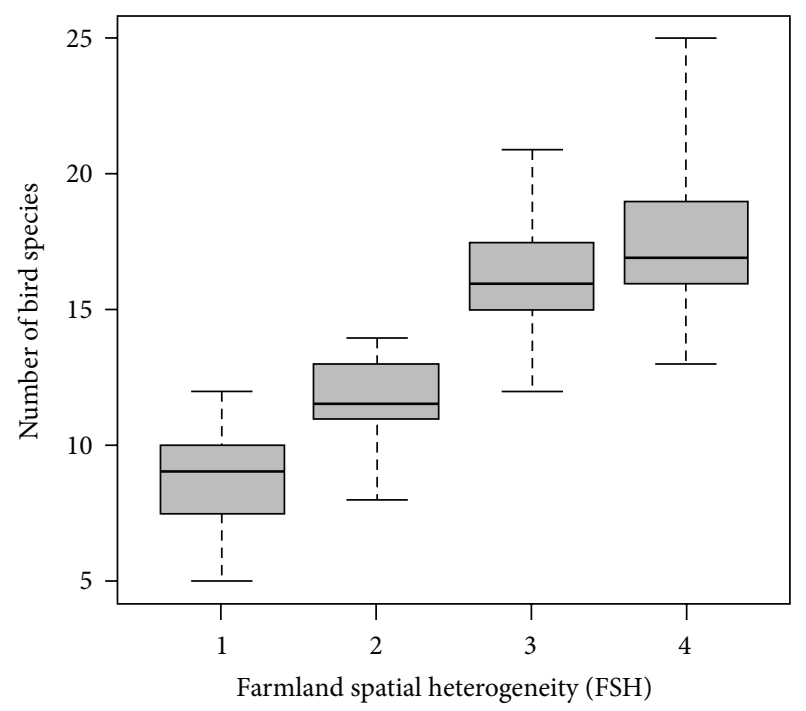

FIGURE 2: Relationship between bird species richness and gradient of spatial heterogeneity of farmlands in Central Italy.

3.3. Bird Species Frequencies on Farmland Type. The bird species most frequently observed in heterogeneous farmlands were Sylvia atricapilla, Turdus merula, and Emberiza cirlus. However, the species present only in this category were Emberiza cirlus and Emberiza calandra, followed by the forest birds Oriolus oriolus, Troglodytes troglodytes, and the raptor Circus pygargus, all considered vulnerable species in the Italian Red List. The only one endangered species recorded was Jynx torquilla.

The bird species most frequently observed in homogeneous farmlands were Passer domesticus italiae, Alauda arvensis, and Motacilla flava, all considered vulnerable species in the Italian Red List (Table 3).

Some species, such as Serinus serinus, Carduelis chloris, and Emberiza hortulana were indistinctly present in farmlands with different level of spatial heterogeneity.

\section{Discussion}

The use of environmental variables collected in situ and adjusted by interpretation of aerial photographs could be more accurate than only GIS analysis. When computing several indexes of fragmentation and spatial heterogeneity on landscapes (e.g., Fragstat and V-Late) the GIS tools working over land cover maps are limited by the spatial resolution of their maps. For this reason they may not be accurate enough in order to quantify small objects as shrubs and short hedges [11, 24, 37]. Although the link between biodiversity and farming practices or landscape structural characteristics has been underlined since the early nineties by Bennett et al. [38] and Beaufoy et al. [39], efforts in characterizing the high natural value of farmland have been carried out more recently [28, 40-42]. The HNV farmland concept has also been embedded in the Common Agricultural Policy (CAP) "to protect and enhance the EU's natural resources and landscapes in rural areas, the resources devoted to axis 2 
TABLE 3: Total frequency (\%), relative frequency, and concern status of bird species [29] in farmlands of Central Italy, classified into different spatial heterogeneity categories.

\begin{tabular}{|c|c|c|c|c|c|c|}
\hline \multirow{2}{*}{ Species } & \multicolumn{4}{|c|}{ FSH category } & \multirow{2}{*}{ Total } & \multirow{2}{*}{ Red List Italy } \\
\hline & $4(n=30)$ & $3(n=28)$ & $2(n=14)$ & $1(n=8)$ & & \\
\hline Sylvia atricapilla & 90 & 96.3 & 84.6 & 62.5 & 86.3 & LC \\
\hline Serinus serinus & 66.7 & 85.2 & 92.3 & 75 & 76.3 & $\mathrm{LC}$ \\
\hline Passer domesticus italiae & 63.3 & 74.1 & 92.3 & 100 & 73.8 & VU \\
\hline Turdus merula & 86.7 & 88.9 & 46.2 & 25 & 72.5 & LC \\
\hline Apus apus & 70 & 77.8 & 84.6 & 50 & 71.3 & $\mathrm{LC}$ \\
\hline Luscinia megarhynchos & 76.7 & 66.7 & 53.8 & 12.5 & 61.3 & $\mathrm{LC}$ \\
\hline Corvus cornix & 76.7 & 77.8 & 23.1 & 25 & 61.3 & $\mathrm{LC}$ \\
\hline Hirundo rustica & 56.7 & 63 & 53.8 & 100 & 61.3 & NT \\
\hline Emberiza cirlus & 80 & 66.7 & 15.4 & 0 & 55 & $\mathrm{LC}$ \\
\hline Fringilla coelebs & 76.7 & 55.6 & 30.8 & 12.5 & 53.8 & LC \\
\hline Sturnus vulgaris & 53.3 & 51.9 & 76.9 & 25 & 52.5 & $\mathrm{LC}$ \\
\hline Streptopelia turtur & 66.7 & 55.6 & 38.5 & 12.5 & 51.3 & $\mathrm{LC}$ \\
\hline Carduelis carduelis & 46.7 & 51.9 & 61.5 & 12.5 & 46.3 & NT \\
\hline Streptopelia decaocto & 40 & 51.9 & 46.2 & 25 & 42.5 & LC \\
\hline Carduelis chloris & 33.3 & 40.7 & 38.5 & 50 & 37.5 & NT \\
\hline Oriolus oriolus & 63.3 & 37 & 0 & 0 & 36.3 & $\mathrm{LC}$ \\
\hline Alauda arvensis & 30 & 25.9 & 46.2 & 62.5 & 33.8 & VU \\
\hline Emberiza hortulana & 36.7 & 29.6 & 53.8 & 12.5 & 33.8 & $\mathrm{DD}$ \\
\hline Emberiza calandra & 50 & 29.6 & 23.1 & 0 & 32.5 & LC \\
\hline Cyanistes caeruleus & 40 & 25.9 & 30.8 & 0 & 28.8 & LC \\
\hline Erithacus rubecula & 30 & 37 & 7.7 & 0 & 25 & LC \\
\hline Parus major & 26.7 & 33.3 & 15.4 & 12.5 & 25 & $\mathrm{LC}$ \\
\hline Garrulus glandarius & 43.3 & 22.2 & 0 & 0 & 23.8 & LC \\
\hline Troglodytes troglodytes & 30 & 33.3 & 0 & 0 & 22.5 & LC \\
\hline Sylvia communis & 33.3 & 18.5 & 15.4 & 0 & 21.3 & LC \\
\hline Phoenicurus phoenicurus & 20 & 22.2 & 7.7 & 12.5 & 17.5 & LC \\
\hline Pica pica & 20 & 22.2 & 7.7 & 12.5 & 17.5 & LC \\
\hline Lanius collurio & 30 & 11.1 & 0 & 12.5 & 16.3 & VU \\
\hline Phasianus colchicus & 6.7 & 14.8 & 30.8 & 25 & 15 & NA \\
\hline Saxicola torquatus & 23.3 & 11.1 & 7.7 & 0 & 13.8 & VU \\
\hline Coturnix coturnix & 13.3 & 14.8 & 7.7 & 12.5 & 12.5 & DD \\
\hline Sylvia cantillans & 23.3 & 7.4 & 0 & 0 & 11.3 & LC \\
\hline Cisticola juncidis & 10 & 3.7 & 15.4 & 25 & 10 & LC \\
\hline Lullula arborea & 10 & 7.4 & 15.4 & 0 & 8.8 & $\mathrm{LC}$ \\
\hline Passer montanus & 0 & 11.1 & 15.4 & 12.5 & 7.5 & VU \\
\hline Corvus monedula & 10 & 3.7 & 7.7 & 0 & 6.3 & LC \\
\hline Dendrocopos minor & 13.3 & 0 & 7.7 & 0 & 6.3 & $\mathrm{LC}$ \\
\hline Picus viridis & 10 & 7.4 & 0 & 0 & 6.3 & $\mathrm{LC}$ \\
\hline Columba palumbus & 6.7 & 7.4 & 0 & 0 & 5 & LC \\
\hline Dendrocopos major & 10 & 3.7 & 0 & 0 & 5 & $\mathrm{LC}$ \\
\hline Merops apiaster & 6.7 & 3.7 & 7.7 & 0 & 5 & LC \\
\hline Regulus ignicapillus & 6.7 & 3.7 & 0 & 0 & 3.8 & $\mathrm{LC}$ \\
\hline Aegithalos caudatus & 6.7 & 0 & 0 & 0 & 2.5 & LC \\
\hline Alectoris rufa & 6.7 & 0 & 0 & 0 & 2.5 & $\mathrm{DD}$ \\
\hline Circus pygargus & 3.3 & 3.7 & 0 & 0 & 2.5 & $\mathrm{VU}$ \\
\hline Columba livia & 3.3 & 3.7 & 0 & 0 & 2.5 & $\mathrm{DD}$ \\
\hline Motacilla alba & 3.3 & 3.7 & 0 & 0 & 2.5 & $\mathrm{LC}$ \\
\hline
\end{tabular}


TABLE 3: Continued.

\begin{tabular}{|c|c|c|c|c|c|c|}
\hline \multirow{2}{*}{ Species } & \multicolumn{4}{|c|}{ FSH category } & \multirow{2}{*}{ Total } & \multirow{2}{*}{ Red List Italy } \\
\hline & $4(n=30)$ & $3(n=28)$ & $2(n=14)$ & $1(n=8)$ & & \\
\hline Motacilla flava & 0 & 0 & 0 & 25 & 2.5 & VU \\
\hline Periparus ater & 6.7 & 0 & 0 & 0 & 2.5 & $\mathrm{LC}$ \\
\hline Phoenicurus ochruros & 3.3 & 3.7 & 0 & 0 & 2.5 & LC \\
\hline Carduelis cannabina & 0 & 3.7 & 0 & 0 & 1.3 & NT \\
\hline Emberiza citrinella & 3.3 & 0 & 0 & 0 & 1.3 & $\mathrm{LC}$ \\
\hline Jynx torquilla & 3.3 & 0 & 0 & 0 & 1.3 & $\mathrm{EN}$ \\
\hline Muscicapa striata & 0 & 3.7 & 0 & 0 & 1.3 & $\mathrm{LC}$ \\
\hline Uрира ерорs & 3.3 & 0 & 0 & 0 & 1.3 & LC \\
\hline
\end{tabular}

TABLE 4: Descriptive elements of agricultural mosaic along the gradient of spatial heterogeneity of farmland in Central Italy.

\begin{tabular}{|c|c|c|c|c|c|c|c|c|}
\hline \multirow{2}{*}{ Environmental parameter } & \multicolumn{5}{|c|}{ FSH category } & \multirow{2}{*}{$F$} & \multirow{2}{*}{ df } & \multirow{2}{*}{$P$ value } \\
\hline & 1 & 2 & 3 & 4 & Total & & & \\
\hline Altitude (m) & $122.7 \pm 77.2$ & $183.3 \pm 156.2$ & $298.8 \pm 168.2$ & $382.5 \pm 129.8$ & $292.4 \pm 168.8$ & 10.1 & 3 & $0.000^{* * *}$ \\
\hline Terrain slope (mode) & Low & Low & Low & Low-medium & Low & - & - & - \\
\hline Roads (mode) & Paved & Paved & Paved & Paved & Paved & - & - & - \\
\hline Powerlines (mean) & $3.1 \pm 2.5$ & $2.9 \pm 2.0$ & $2.5 \pm 1.6$ & $3.8 \pm 2.8$ & $3.1 \pm 2.3$ & 1.5 & 3 & 0.221 \\
\hline Crop diversity (mean) & $0.632 \pm 0.3$ & $0.554 \pm 0.3$ & $0.533 \pm 0.4$ & $0.489 \pm 0.4$ & $0.530 \pm 0.3$ & 0.3 & 3 & 0.790 \\
\hline
\end{tabular}

Significance codes: ${ }^{* * *} P<0.001,{ }^{* *} P<0.01,{ }^{*} P<0.05,{ }^{*} P<0.1$.

TABLE 5: Similarity index pairwise of the bird species richness among the farmlands according to their spatial heterogeneity gradient.

\begin{tabular}{lccccc}
\hline \multirow{2}{*}{ FSH category } & \multicolumn{5}{c}{ Similarity index } \\
& 1 & 2 & 3 & 4 & Total \\
\hline 1 & - & 0.780 & 0.667 & 0.605 & 0.472 \\
2 & - & - & 0.815 & 0.776 & 0.764 \\
3 & - & - & - & 0.959 & 0.922 \\
4 & - & - & - & - & 0.962 \\
Number of bird species (total) & 25 & 34 & 47 & 51 & 55 \\
\hline
\end{tabular}

should contribute to three EU-level priority areas: biodiversity and the preservation and development of HNV farming and forestry systems and traditional agricultural landscapes water and climate change" (Community's Strategic Guidelines for rural development, 2007-2013, OJL55/20, 2006). The $\mathrm{HNV}$ is characterized by three main criteria: low intensity farming, presence of semi-natural vegetation (hedgerows, uncultivated, shrubs, etc.), and diversity of land cover mosaic.

The results showed how in Central Italy bird richness is related to spatial heterogeneity of farmlands, highlighting how the lack of several features, such hedgerows or scattered shrubs, causes the loss of more than $53 \%$ of the total potential bird species richness. These findings point out the important role of these few marginal components, typical of most heterogeneous mosaics, corresponding to HNV farmlands. The results also show that diversity of land-use rather than crop types seems to be important for bird species richness in farmlands. However, because these two variables are correlated, is hard determinate the real contribution of each one. Shannon index of crop types decreases with farmland heterogeneity, because diversity of crop types corresponds to more extended and less complex farmlands from a structural point of view. The characteristics of farmlands seeming to support high numbers of bird species are hedgerows, scattered shrubs, uncultivated patches, and the presence of power lines. The first three elements could improve the landuse diversity, offering habitat availability to several species $[7,9,43]$. Other studies underlined how electricity wires may offer useful perches and singing posts, representing attractive structures to insectivorous and to those birds hunting from observation posts like the Lanidae [44, 45]. Moreover, a positive effect on bird detection may also be considered. However, the same structures could be dangerous and cause mortality by collision or electrocutions for several raptors species that were excluded in this study [46, 47]. In our study, the absence of all these features and structural items is associated with a deep decrease of biodiversity.

The comparison between similarities index provided a quantitative measure of the total influence of the spatial heterogeneity on bird community. The approach by mean of Sorensen index can constitute an easy and fast decisional tool, useful to compare and quantify how a gradient of urbanization can modify the biodiversity of ecosystems [48]. The quantification of the impact of landscape or land-use features on the biodiversity can constitute a useful tool for conservation planning, landscape restoring, and for maintaining HNV farmlands.

The results of this work can be useful to select the most important environmental parameters to maintain the biodiversity and to characterize the bird communities or the presence of threatened species on different farmland types too. The bird species frequencies on farmland types are 
TABLE 6: Different candidate models, ranked according to the AIC values, used to select the best models to relate bird richness to landscape, land-use, and crop types in farmlands of Central Italy.

\begin{tabular}{|c|c|c|c|}
\hline Variables included in the model & Total number of variables & Scale level & AIC \\
\hline $\begin{array}{l}\text { Alt }+ \text { slo }+ \text { pow }+ \text { shr }+ \text { for }+ \text { unc }+ \text { bad }+ \text { gra }+ \text { hed }+ \text { tre }+ \\
\text { urb }+ \text { cul }+ \text { ofo }+ \text { whe }+ \text { alf }+ \text { hay }+ \text { sun }+ \text { cri }+ \text { sug }+ \text { cor }+ \\
\text { gar }+ \text { oat }+ \text { bra }+ \text { let }+ \text { land-use div }\end{array}$ & 25 & Landscape, land-use, crop type & 424.53 \\
\hline $\begin{array}{l}\text { Alt }+ \text { slo }+ \text { pow }+ \text { shr }+ \text { for }+ \text { unc }+ \text { bad }+ \text { gra }+ \text { hed }+ \text { tre }+ \\
\text { urb }+ \text { cul }\end{array}$ & 12 & Landscape, land-use & 429.73 \\
\hline Alt + pow + shr + unc + bad + gra + hed + urb & 8 & Landscape, land-use & 422.51 \\
\hline Pow + shr + unc + hed & 4 & Landscape, land-use & 417.31 \\
\hline
\end{tabular}

TABLE 7: Results of Poisson regression for the best model relating the bird species richness to environmental parameters of farmlands in Central Italy. The table shows the most significant variables selected after a stepwise backward procedure using AIC criterion. A comparison of models with all possible variables, classified in the four different categories of spatial heterogeneity, showed that the significant parameters are the same for all the evaluated levels.

\begin{tabular}{lcccc}
\hline $\begin{array}{l}\text { Environmental } \\
\text { parameter }\end{array}$ & Estimate & SE & $Z$ value & $P$-values \\
\hline $\begin{array}{l}\text { Farmlands } \\
(n=80)\end{array}$ & & & & \\
$\quad$ Powerlines & 0.02805 & 0.01242 & 2.257 & $0.0240^{*}$ \\
$\quad$ Shrubs & 1.23966 & 0.50681 & 2.446 & $0.0144^{*}$ \\
Uncultivated & 0.94663 & 0.53777 & 1.760 & 0.0784 \\
$\quad$ Hedgerows & 1.51644 & 0.33585 & 4.515 & $6.33 e-06^{* * *}$ \\
Intercept & 2.21632 & 0.09018 & 24.576 & $2 e-16^{* * *}$ \\
\hline Significance codes: ${ }^{* * *} P<0.001,{ }^{* *} P<0.01,{ }^{*} P<0.05$, & ${ }^{*} P<0.1$.
\end{tabular}

useful to develop any bioindicator approach (farmland bird index, monitoring of HNV farmlands, farmland focal species, etc.). For example Italian Sparrow, in decreasing throughout the whole Italian peninsula [49], was present mainly in homogeneous farmlands, almost twice times if compared to the only 11 records from more heterogeneous fields. The Ortolan Bunting that is considered in decline in Europe [50-54] did not show preferences between homogeneous or heterogeneous farmlands. The Western Yellow Wagtail was present only in farmlands with less spatial heterogeneity and completely absent in more heterogeneous fields. On the other hand, some species only occur in very heterogeneous farmlands and could be targeted as good indicators of biodiversity in farmlands, in the sense of the "focal species" approach [55]. Two typical farmland birds mainly present in more heterogeneous farmlands were the Cirl Bunting and the Corn Bunting (Table 3).

Finally, our results help filling the lack of data about farmland bird ecology in southern Europe [17] and suggest the necessity of coordinating the management actions established by conservations plans and the different farmlands involved, possibly through an agricultural policy on a regional scale, according to the guidelines of detailed $\mathrm{EU}$ rural policies. The importance found for several features such as linear hedgerows can suggest conservation policies as the creation and maintenance of hedges, field margins, retention of uncropped areas, or the use of intercropping cultures in the fields this way we can increase the spatial heterogeneity and help to enhancing, thus favoring the settlement of several concern bird species $[9,29,56]$. Furthermore, the importance of using species-specific strategies for maintaining and preserving the structure and the functionality of agroecosystems is highlighted, as the necessity of more local scale studies, from the applied point of view, considering that currently the farmland environment in Central-Eastern Europe is generally more extensive and more complex than in Western Europe, and this fact generates different biodiversity conditions in agricultural areas [57].

\section{Acknowledgments}

The author is very grateful to the following people: Dan Chamberlain, Jon Mc Kean, Marco Girardello, Raffaele Secchi, Maria Balsamo, Yanina Benedetti, and anonymous reviewers for their suggestions or valuable comments on earlier versions of the manuscript or in the field. He also thanks ION Proofreading for the critical revision of English version of the paper.

\section{References}

[1] D. E. Chamberlain, R. J. Fuller, R. G. H. Bunce, J. C. Duckworth, and M. Shrubb, "Changes in the abundance of farmland birds in relation to the timing of agricultural intensification in England and Wales," Journal of Applied Ecology, vol. 37, no. 5, pp. 771-788, 2000.

[2] P. F. Donald, R. E. Green, and M. F. Heath, "Agricultural intensification and the collapse of Europe's farmland bird populations," Proceedings of the Royal Society B, vol. 268, no. 1462, pp. 25-29, 2001.

[3] D. Kleijn, F. Kohler, A. Báldi et al., "On the relationship between farmland biodiversity and land-use intensity in Europe," Proceedings of the Royal Society B, vol. 276, no. 1658, pp. 903-909, 2009.

[4] A. C. Weibull, Ö. Östman, and Å. Granqvist, "Species richness in agroecosystems: the effect of landscape, habitat and farm management," Biodiversity and Conservation, vol. 12, no. 7, pp. 1335-1355, 2003.

[5] G. M. Siriwardena, H. Q. P. Crick, S. R. Baillie, and J. D. Wilson, "Agricultural land-use and the spatial distribution of granivorous lowland farmland birds," Ecography, vol. 23, no. 6, pp. 702-719, 2000. 
[6] J. R. Krebs, J. D. Wilson, R. B. Bradbury, and G. M. Siriwardena, “The second silent spring?" Nature, vol. 400, no. 6745, pp. 611612, 1999.

[7] H. J. W. Vermeulen, "Corridor function of a road verge for dispersal of stenotopic heathland ground beetles Carabidae," Biological Conservation, vol. 69, no. 3, pp. 339-349, 1994.

[8] J. Hoffmann and J. M. Greef, "Mosaic indicators-theoretical approach for the development of indicators for species diversity in agricultural landscapes," Agriculture, Ecosystems and Environment, vol. 98, no. 1-3, pp. 387-394, 2003.

[9] T. G. Benton, J. A. Vickery, and J. D. Wilson, "Farmland biodiversity: is habitat heterogeneity the key?" Trends in Ecology and Evolution, vol. 18, no. 4, pp. 182-188, 2003.

[10] F. Morelli, "Importance of road proximity for the nest site selection of the Red-backed shrike Lanius collurio in an agricultural environment in Central Italy," Journal of Mediterranean Ecology, pp. 21-29, 2011.

[11] F. Morelli, R. Santolini, and D. Sisti, "Breeding habitat of Redbacked Shrike Lanius collurio on farmland hilly areas of Central Italy: is functional heterogeneity an important key?" Ethology Ecology \& Evolution, vol. 24, pp. 127-139, 2012.

[12] L. Norton, P. Johnson, A. Joys et al., "Consequences of organic and non-organic farming practices for field, farm and landscape complexity," Agriculture, Ecosystems and Environment, vol. 129, no. 1-3, pp. 221-227, 2009.

[13] N. A. Beecher, R. J. Johnson, J. R. Brandle, R. M. Case, and L. J. Young, "Agroecology of birds in organic and nonorganic farmland," Conservation Biology, vol. 16, no. 6, pp. 1620-1631, 2002.

[14] Y. Kisel, L. Mcinnes, N. H. Toomey, and C. D. L. Orme, "How diversification rates and diversity limits combine to create largescale species-area relationships," Philosophical Transactions of the Royal Society B, vol. 366, no. 1577, pp. 2514-2525, 2011.

[15] D. J. Pain and M. W. Pienkowski, Eds., Birds and Farming in Europe: The Common Agricultural Policy and Its Implications for Bird Conservation, Academic Press, San Diego, Calif, USA, 1997.

[16] D. Kleijn and W. J. Sutherland, "How effective are European agri-environment schemes in conserving and promoting biodiversity?" Journal of Applied Ecology, vol. 40, no. 6, pp. 947-969, 2003.

[17] A. Báldi and P. Batáry, "Spatial heterogeneity and farmland birds: different perspectives in Western and Eastern Europe," Ibis, vol. 153, no. 4, pp. 875-876, 2011.

[18] P. Batáry, A. Báldi, and S. Erdős, "Grassland versus nongrassland bird abundance and diversity in managed grasslands: local, landscape and regional scale effects," Biodiversity and Conservation, vol. 16, no. 4, pp. 871-881, 2007.

[19] P. Batáry, J. Fischer, A. Báldi, T. O. Crist, and T. Tscharntke, "Does habitat heterogeneity increase farmland biodiversity?" Frontiers in Ecology and the Environment, vol. 9, no. 3, pp. 152153, 2011.

[20] R. Barbault, La Biodiversité: Introduction à la Biologie de la Conservation, Collection les Fondamentaux, Hachette, Paris, France, 1997.

[21] C. J. Bibby, N. D. Burgess, and D. A. Hill, Bird Census Techniques, Academic Press, London, UK, 1997.

[22] R. Clarke, Montagu's Harrier, Arlequin Press, Chelmsford, UK, 1996.

[23] B. Arroyo, J. T. García, and V. Bretagnolle, "Conservation of the Montagu's harrier (Circus pygargus) in agricultural areas," Animal Conservation, vol. 5, no. 4, pp. 283-290, 2002.
[24] M. Brambilla, F. Casale, V. Bergero et al., "GIS-models work well, but are not enough: habitat preferences of Lanius collurio at multiple levels and conservation implications," Biological Conservation, vol. 142, no. 10, pp. 2033-2042, 2009.

[25] D. Baldock, G. Beaufoy, G. Bennett, and J. Clark, Nature Conservation and New Directions in the Common Agricultural Policy, Institute for European Environmental Policy, London, UK, 1993.

[26] E. M. Bignal and D. I. McCracken, "Low-intensity farming systems in the conservation of the countryside," Journal of Applied Ecology, vol. 33, no. 3, pp. 413-424, 1996.

[27] E. Andersen, D. Baldock, H. Bennett et al., "Developing a High Nature Value Farming area indicator," Report for the European Environment Agency, Copenhagen, Denmark, 2003, http:// www.ieep.eu/assets/646/Developing_HNV_indicator.pdf.

[28] P. Pointereau, M. L. Paracchini, J.-M. Terres, F. Jiguet, Y. Bas, and K. Biala, "Identification of high nature value farmland in France through statistical information and farm practice surveys," Report EUR 22786 EN, Office for Official Publications of the European Communities, Brussels, Luxembourg, 2007.

[29] V. Peronace, J. G. Cecere, M. Gustin, and C. Rondinini, "Lista Rossa 2011 degli uccelli nidificanti in Italia," Avocetta, vol. 36, pp. 11-58, 2012.

[30] P. F. Donald and C. Forrest, "The effects of agricultural change on population size of corn buntings Miliaria calandra on individual farms," Bird Study, vol. 42, no. 3, pp. 205-215, 1995.

[31] R. H. G. Jongman, C. J. F. ter Braak, and O. F. R. Tongeren, Data Analysis in Community and Landscape Ecology, Cambridge University Press, Cambridge, UK, 1995.

[32] P. McCullagh and J. A. Nelder, Generalized Linear Models, Chapman and Hall, London, UK, 1989.

[33] H. Akaike, "A new look at the statistical model identification," IEEE Transactions on Automatic Control, vol. 19, no. 6, pp. 716723, 1974.

[34] Anon, S-PLUS 2000 Guide to Statistics, vol. 1, MathSoft, Seattle, Wash, USA, 1999.

[35] M. G. Betts, A. W. Diamond, G. J. Forbes, M. A. Villard, and J. S. Gunn, "The importance of spatial autocorrelation, extent and resolution in predicting forest bird occurrence," Ecological Modelling, vol. 191, no. 2, pp. 197-224, 2006.

[36] J. Oksanen, F. G. Blanchet, R. Kindt et al., "vegan: Community Ecology Package. R package version 2.0-6," 2013, http://CRAN.R-project.org/package=vegan.

[37] F. Morelli, "Plasticity of habitat selection by red-backed shrikes Lanius collurio breeding in different landscapes," The Wilson Journal of Ornithology, vol. 124, pp. 52-57, 2012.

[38] A. F. Bennett, J. Q. Radford, and A. Haslem, "Properties of land mosaics: implications for nature conservation in agricultural environments," Biological Conservation, vol. 133, no. 2, pp. 250 264, 2006.

[39] G. Beaufoy, D. Baldock, and J. Clark, The Nature of Farming: Low Intensity Farming Systems, in Nine European Countries, Institute for European Environmental Policy, London, UK, 1994.

[40] EENRD/EC, "Guidance document. The application of the High Nature Value impact indicator. European Communities," 2009, http://ec.europa.eu/agriculture/rurdev/eval/hnv/ guidance_en.pdf.

[41] M. L. Paracchini, J.-M. Terres, E. Petersen et al., "High nature value farmland in Europe. An estimate of the distribution patterns on the basis of land cover and biodiversity data. European Commission Joint Research Centre, Institute for 
Environment and Sustainability," Report EUR 23480 EN, Office for Official Publications of the European Communities, Brussels, Luxembourg, 2008.

[42] European Environment Agency, "High nature value farmland: characteristics, trends and policy challenges," EEA Report No. 1/2004, Copenhagen, Denmark, 2004.

[43] H. J. W. Vermeulen and P. F. M. Opdam, "Effectiveness of roadside verges as dispersal corridors for small ground-dwelling animals: a simulation study," Landscape and Urban Planning, vol. 31, no. 1-3, pp. 233-248, 1995.

[44] A. Bechet, P. Isenmann, and R. Gaudin, "Nest predation, temporal and spatial breeding strategy in the Woodchat Shrike Lanius senator in Mediterranean France," Acta Oecologica, vol. 19, no. 1, pp. 81-87, 1998.

[45] N. Lefranc, Les Pies-grieches d'Europa, d'Afrique du nord et $d u$ moyen-Orient, Delachaux et Niestlé S.A., Lausanne, Paris, France, 1993.

[46] R. E. Harness and K. R. Wilson, "Electric-utility structures associated with raptor electrocutions in rural areas," Wildlife Society Bulletin, vol. 29, no. 2, pp. 612-623, 2001.

[47] K. Bevanger, "Biological and conservation aspects of bird mortality caused by electricity power lines: a review," Biological Conservation, vol. 86, no. 1, pp. 67-76, 1998.

[48] P. Clergeau, S. Croci, J. Jokimäki, M. L. Kaisanlahti-Jokimäki, and M. Dinetti, "Avifauna homogenisation by urbanisation: analysis at different European latitudes," Biological Conservation, vol. 127, no. 3, pp. 336-344, 2006.

[49] L. Fornasari, E. de Carli, L. Buvoli et al., "Secondo bollettino del progetto MITO2000: valutazioni metodologiche per il calcolo delle variazioni interannuali," Avocetta, vol. 28, pp. 59-76, 2004.

[50] S. Dale, "Causes of population decline of the Ortolan Bunting in Norway," in Bunting Studies in Europe, P. Tryjanowski, T. S. Osiejuk, and M. Kupczyk, Eds., pp. 33-41, Bogucki Wydawnictwo Naukowe, Poznan, Poland, 2001.

[51] P. F. Donald, F. J. Sanderson, I. J. Burfield, and F. P. J. van Bommel, "Further evidence of continent-wide impacts of agricultural intensification on European farmland birds, 19902000," Agriculture, Ecosystems and Environment, vol. 116, no. 34, pp. 189-196, 2006.

[52] F. Morelli, "Correlations between landscape features and crop type and the occurrence of the Ortolan Bunting Emberiza hortulana in farmlands of Central Italy," Ornis Fennica, vol. 89, pp. 264-272, 2012.

[53] I. Newton, "The recent declines of farmland bird populations in Britain: an appraisal of causal factors and conservation actions," Ibis, vol. 146, no. 4, pp. 579-600, 2004.

[54] G. M. Tucker and M. F. Heath, Birds in Europe: Their Conservation Status, BirdLife Conservation Series no. 3, BirdLife International, Cambridge, UK, 1994.

[55] R. J. Lambeck, "Focal species: a multi-species umbrella for nature conservation," Conservation Biology, vol. 11, no. 4, pp. 849-856, 1997.

[56] M. J. Whittingham and K. L. Evans, "The effects of habitat structure on predation risk of birds in agricultural landscapes," Ibis, vol. 146, no. 2, pp. 210-220, 2004.

[57] P. Tryjanowski, T. Hartel, A. Báldi et al., "Conservation of farmland birds faces different challenges in Western and CentralEastern Europe," Acta Ornithologica, vol. 46, no. 1, pp. 1-12, 2011. 

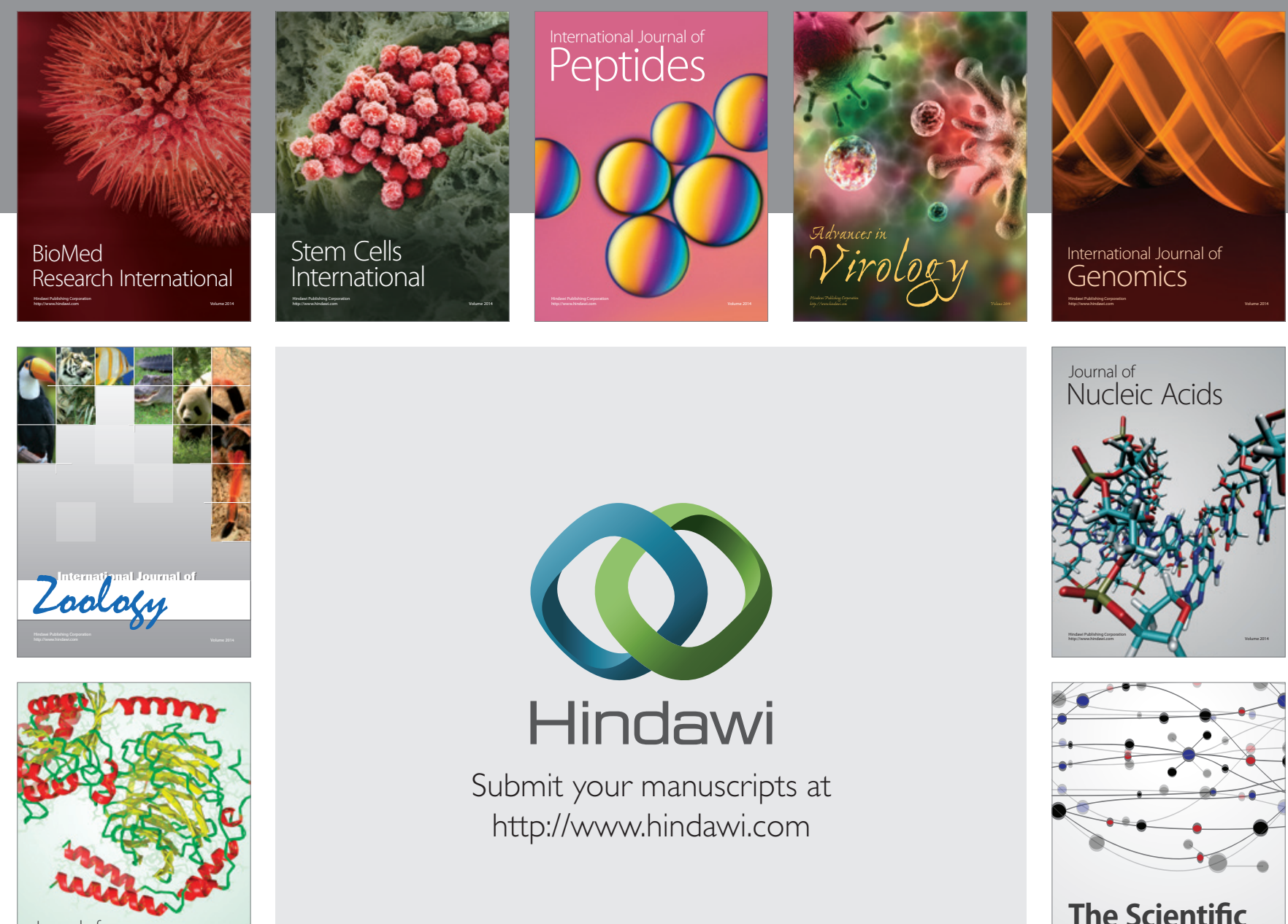

Submit your manuscripts at

http://www.hindawi.com

Journal of
Signal Transduction
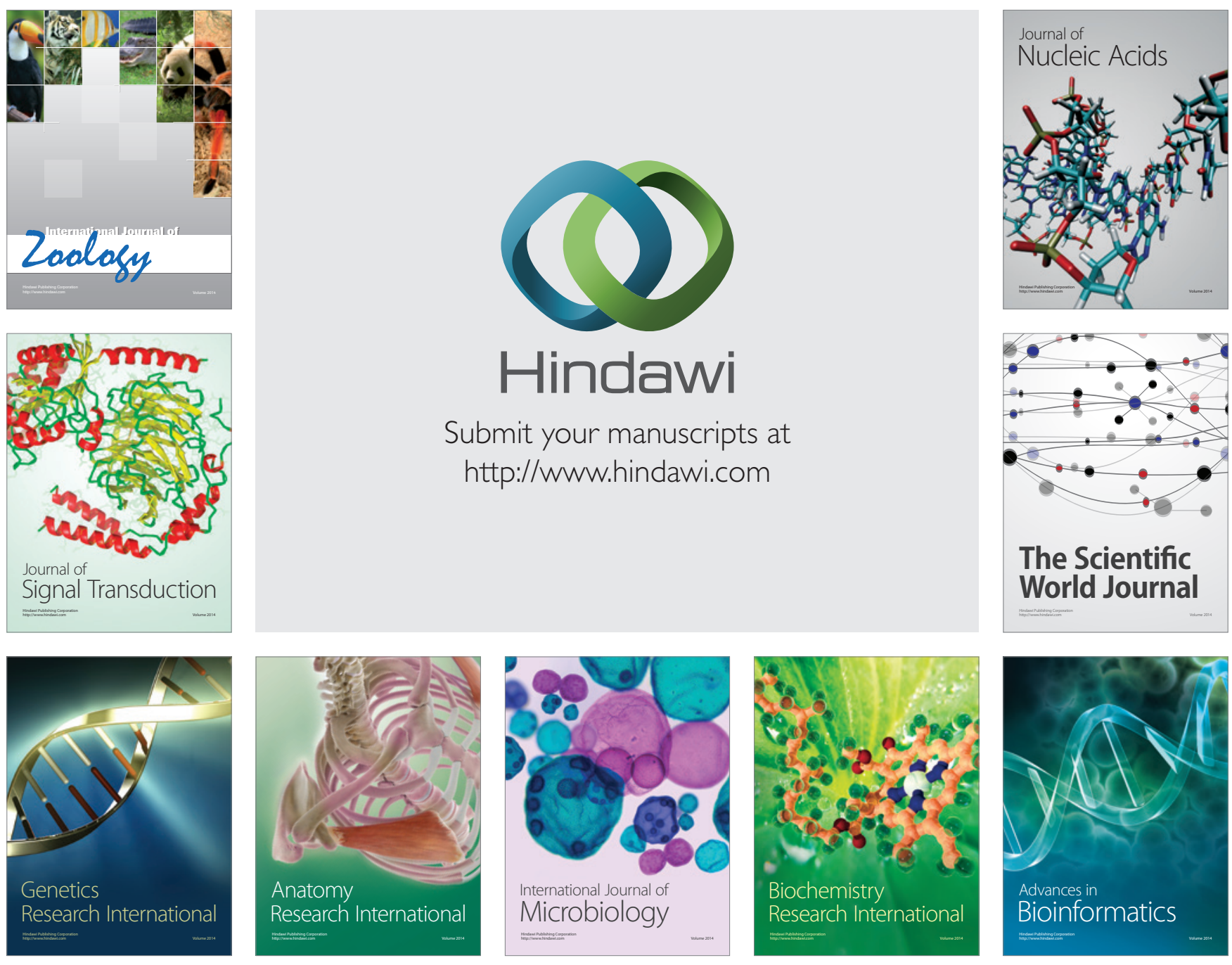

The Scientific World Journal
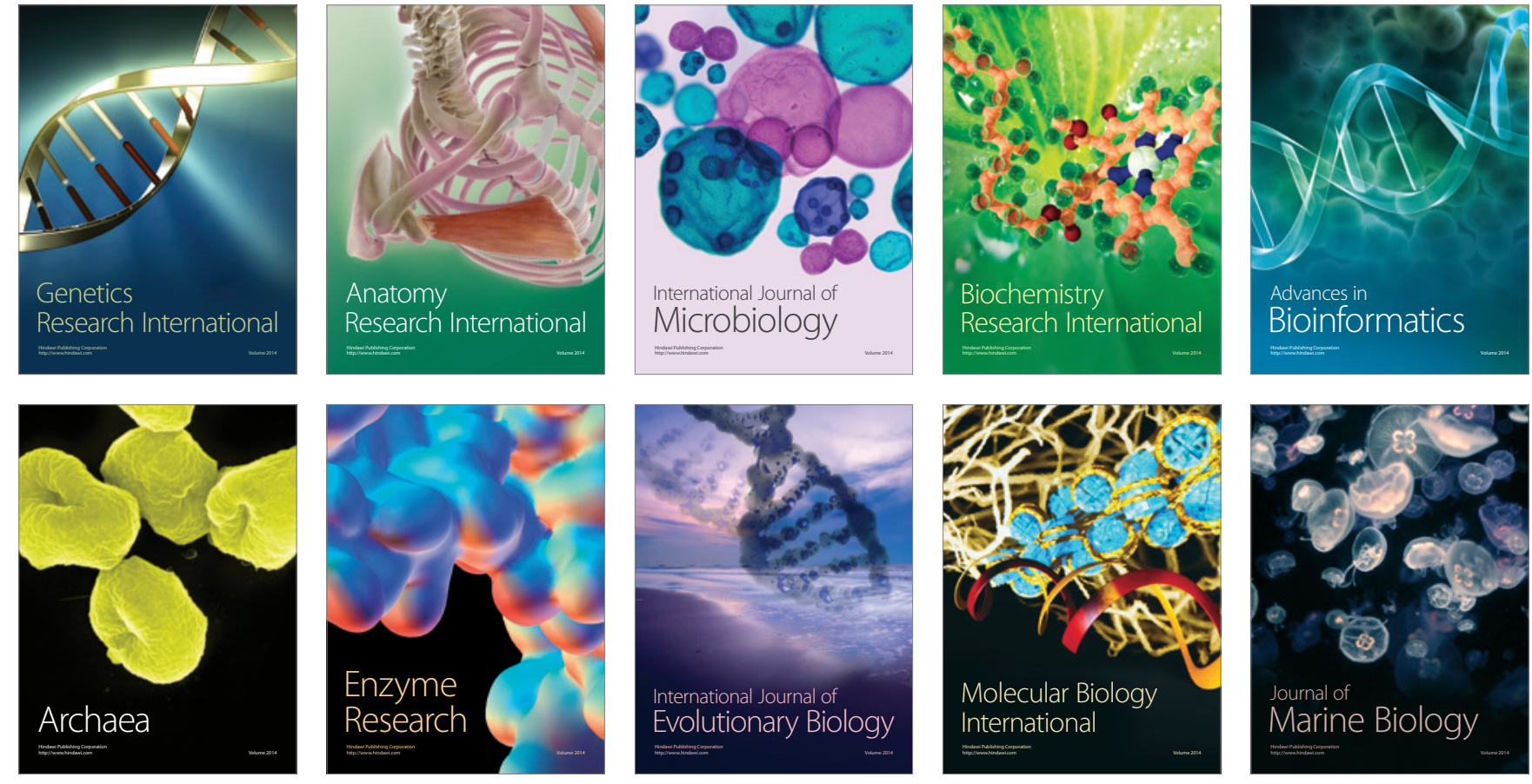